This document is published in:

P. G. Esteban, Y. Thomas, E. Baril, E. M. Ruiz-Navas, E. Gordo, Study of Compaction and Ejection of Hydrided-Dehydrided Titanium Powder, Metals and Materials International, Feb. 2011, 17(1), 45-55, DOI: http://dx.doi.org/10.1007/s12540-011-0207-z

(C) KIM and Springer 


\title{
Study of Compaction and Ejection of Hydrided-Dehydrided Titanium Powder
}

\author{
P. G. Esteban ${ }^{1}$, Y. Thomas ${ }^{2}$, E. Baril ${ }^{2}$, E. M. Ruiz-Navas ${ }^{1}$, and E. Gordo ${ }^{1, *}$ \\ ${ }^{1}$ Department of Materials Science and Engineering, IQMAAB, University Carlos III ofe Madrid, \\ Avda. de la Universidad 30, 28911 Leganés (Madrid), Spain \\ ${ }^{2}$ Industrial Materials Institute (IMI), National Research Council Canada (CNRC-NRC), \\ 75 de Mortagne Boulevard, Boucherville (Quebec), J4B 6Y4, Canada
}

(received date: 2010 / accepted date: 2010)

\begin{abstract}
Three similar varieties of pure Ti hydride-dehydried (HDH) powders were tested for the understanding of the variables that have an influence on the compaction process of Ti powders. The study shows that small differences in the characteristics of the powders lead to very different behaviours in the compaction stage. Compressibility curves, friction with the die walls and ejection forces are discussed in this study. The results are compared with a commercial iron powder as a reference to complete the discussion, as well as to show the enhancements and modifications that should be performed in Ti powders to design an optimized powder suitable for being pressed in an industrial process.
\end{abstract}

Keywords: titanium hydride-dehydried(HDH), uniaxial pressing, compressibility

\section{INTRODUCTION}

The excellent combination of specific strength and corrosion resistance of titanium and titanium alloys $[1,2]$ encourages the development of low cost processes to obtain Ti parts. Moreover, some studies [3] predict the decrease of the prices of Ti due to new production techniques for obtaining Ti from its ores. Among these new techniques, the Armstrong process [4] is ready for production, and other incoming developments based on electrolytic methods could be even more efficient in obtaining Ti at low cost. Among the electrolytic methods, the FFC development [5] seems to be the most promising to obtain Ti powder by the direct reduction of $\mathrm{TiO}_{2}$. Other works $[6,7]$ have studied the benefits that Ti would provide in the reduction of emissions in vehicles. This conjunction of factors encourages industry to develop the powder metallurgy technology for Ti.

Powder metallurgy has provided a low-cost route for manufacturing iron-based parts and the related processes are now optimized since they have been studied for a long time. On the other hand, Ti is emerging as a good candidate for being processed by conventional powder metallurgy techniques, but improvements should be done to reach the optimization of the processes. Ti powder industry has been restricted to high-added value applications where the cost of the materi-

*Corresponding author: egordo@ing.uc3m.es ○KIM and Springer als and processes are not fully optimized for large scale productions. The traditional and potential applications include military, sports, aerospace, medical and automotive $[8,9]$. Biomedical applications are promising to continue the development of Ti technology, including PM processing [10-13].

Few papers have studied the compaction of Ti powders [14-18]. This work is focused on the different aspects related to the uniaxial pressing of Ti powder in comparison with the well-known behaviour of commercial iron powder. As it will be shown in this study, the significant difference between titanium and iron is reflected in their relative pressing performances.

Regarding the type of Ti powder used for this study, the Hydried-dehydried powder (Ti HDH) has been selected due to the higher purity than sponge powder, and irregular shape compared to atomised powder, providing better characteristics for powder metallurgy processing. Ti $\mathrm{HDH}$ is a common variety of Ti powder which is produced by the comminution of Ti solids which have been previously embrittled. In a first stage, Ti solids are heated into a furnace in a hydrogen atmosphere. Then, the solids loose their natural ductility by hydrogen embrittlement, leading to hydrided Ti. In a second stage, hydrided Ti solids are easily comminuted to the desire powder size. In a final stage, hydrided Ti powder must be dehydried to recover its original ductility and properties. This is achieved by heating Ti powder into a vacuum furnace, where degassing of the material occurs. 


\section{EXPERIMENTAL PROCEDURE}

All experiments were carried out using hydride-dehydride (HDH) titanium powders and water-atomized iron powder, compacted with admixed lubricant or with die-wall lubricant. Table 1 describes the type of powders tested, their supplier, and the lubrication mode used in each case. In particular, two batches of the similar powder (Ti, HDH process, $<75 \mu \mathrm{m}$ ) sold under the same tradename were evaluated (Batch 1 and Batch 2).

Apparent density was measured using the standards MPIF 4 and MPIF $28[19,20]$. Particle size distributions of the different powders were measured with a laser diffraction particle size analyzer (Beckman Coulter LS 13 320, USA). Chemical analyses were carried out on LECO analyzers, LECO TCH-600 for oxygen, nitrogen and hydrogen, and LECO CS-200 for carbon and sulphur. Specific surface of the powders was measured by the BET technique, using a Monosorb Surface Area equipment, from Quantachrome Corporation (USA), model MS-13.

Micro-hardness of the different powders was also evaluated in a Vickers micro-hardness tester, model HVS-1000 (TIME Technology Europe). Ten $\mathrm{HV}_{0.01}$ measurements were carried out for each type of powder, at a load of $0.098 \mathrm{~N}$. The same range of particle size was selected to better compare the powders, and avoid size-effects in the measurements.

The behaviour of the different powders during compaction and ejection was evaluated using an instrumented laboratory press, the Powder Testing Centre (PTC) [21]. This apparatus consists of an instrumented cylindrical die operating in a single action mode. This press allows continuous recording of the applied pressure and the pressure transmitted to the stationary punch during the compaction and ejection processes. Assuming a rigid behaviour of the die, this press allows the quantification of the three key properties or factors affecting the green density, namely the friction at die walls, the powder intrinsic compressibility and the expansion at ejection, as described in the next section [22].

For all experiments, cylindrical specimens of $7 \mathrm{~mm}$ in height were compacted at $500 \mathrm{MPa}$ at room temperature in a WC-Co die of $9.525 \mathrm{~mm}$ in diameter, and at a pressing rate of $1 \mathrm{~mm} / \mathrm{s}$. At least seven samples were tested for each condition, and the two first tests were used to condition the die walls and were not considered for the calculations. Results presented in this study show good reproducibility and correspond to average values obtained from at least five specimens.

As described in Table 1, die wall lubrication was used to minimize contamination of titanium. A thin layer of zinc stearate was applied on the die walls using a semi-automated device adapted to the PTC, based on the same principles of the patented electrostatic system for industrial presses [23,24]. In this system, lubricant particles are tribostatically charged when they are carried by a flow of air through a small Teflon tube, and are injected in the die cavity in such a way to minimize turbulence. Excess of lubricant is evacuated through exhaust vents located on the die cover plate. On the other hand, iron powders were compacted either with admixed lubricant or using die wall lubrication.

\subsection{Analysis of the compaction process}

The PTC enables to analyze the compaction process in a rigid die as a function of two fundamental parameters: the slide coefficient $\eta$, which measures the friction between powder particles and die walls, and the intrinsic compressibility, which measures the reaction of a powder to an outside pressure.

The intrinsic compressibility can be expressed by the relation between the average in-die density and the average pressure seen by the compact. Considering that the density varies linearly along the compaction axis as shown by several researchers $[25,26]$, it can be stated that the density at midheight is equal to the average density. Therefore, the average pressure or net pressure, $\mathrm{P}_{\mathrm{NET}}$ can be evaluated at mid-height of the compact with equation 1 for a cylindrical compact:

$$
P_{N E T}=P a^{*} \eta^{\left(\frac{H}{2 D}\right)}=(P a * P t)^{1 / 2}
$$

where $\mathrm{Pa}$ is the pressure applied to the compacting punch, $\mathrm{Pt}$ the pressure transmitted to the stationary punch, $\eta$ the sliding coefficient, $\mathrm{H}$ the height of the compact, and $\mathrm{D}$ the diameter of the compact.

It should be emphasized that the intrinsic compressibility is only dependant on the intrinsic mechanical behavior of the powder during compaction. On the other hand, the compressibility, which is defined as the pressure required to reach a given density or the density obtained for a given

Table 1. Powders and lubrication used

\begin{tabular}{|c|c|c|c|c|}
\hline & Powder & Supplier & Mode of Lubrication & Lubricant \\
\hline \multirow{3}{*}{ Titanium Powders } & $\mathrm{Ti}-$ Batch 1 & $\mathrm{GfE} *$ & Die-Wall & Zinc Stearate \\
\hline & $\mathrm{Ti}-$ Batch 2 & GfE* & Die-Wall & Zinc Stearate \\
\hline & $\mathrm{Ti}-$ Batch 3 & $\mathrm{GfE}^{*}$ & Die-Wall & Zinc Stearate \\
\hline \multirow{2}{*}{ Iron Powders } & ASC100.29 & Höganäs** & Die-Wall & Zinc Stearate \\
\hline & ASC100.29 & Höganäs** & Admixed & $0.7 \% \mathrm{EBS} * * *$ \\
\hline
\end{tabular}

*GfE Metalle und Materialien Gmbh, Germany

**Höganäs, Sweden

***EBS: ethylene bisstearamide (ACRAWAX C from Lonza) 
pressure, is influenced not only by the powder intrinsic compressibility but also by the friction at die walls and by the expansion at ejection. In particular, the compact size or aspect ratio strongly affects the amount of friction at the die walls and therefore the compressibility, while the intrinsic compressibility is, on the contrary, independent of the compact aspect ratio.

The compaction process can also be described by the determination of a slide coefficient $\eta$, which gives an evaluation of the level of friction between powder particles and die walls. The slide coefficient $\eta$ characterizes the efficiency of transferring the compaction force throughout the part and the densification uniformity. The slide coefficient is given by equation 2 ,

$$
\eta=\left(\frac{P t}{P a}\right)^{\left\lceil\frac{4 F}{S H}\right]}
$$

where $\mathrm{Pa}$ is the pressure applied to the compacting punch, $\mathrm{Pt}$ the pressure transmitted to the stationary punch, $\mathrm{F}$ the crosssection area, $\mathrm{S}$ the cross-section perimeter and $\mathrm{H}$ the height.

The factor $4 \mathrm{~F} / \mathrm{SH}$ represents the compact aspect ratio or compact geometry factor. For a cylindrical compact, the factor $4 \mathrm{~F} / \mathrm{SH}$ is equal to $\mathrm{D} / \mathrm{H}$ where $\mathrm{D}$ is the diameter of the compact. $\eta$ can vary between 0 and 1,0 representing an infinite friction and 1 no friction. Thus, the higher the $\eta$, the lower the friction loss and the better the lubrication and densification uniformity. For a given in-die density, the value of the slide coefficient proved to be a good parameter to compare the lubrication behavior of similar steel powder mixes containing different types of lubricants[22,27, 28]. However, the value of slide coefficient is far from being constant through the pressing process. The variation of the slide coefficient results, in fact, from the complex evolution of the friction coefficient and the angle of pressure transmission or radial to axial stress ratio. However, at high pressures, the relative movement of particles becomes negligible and the

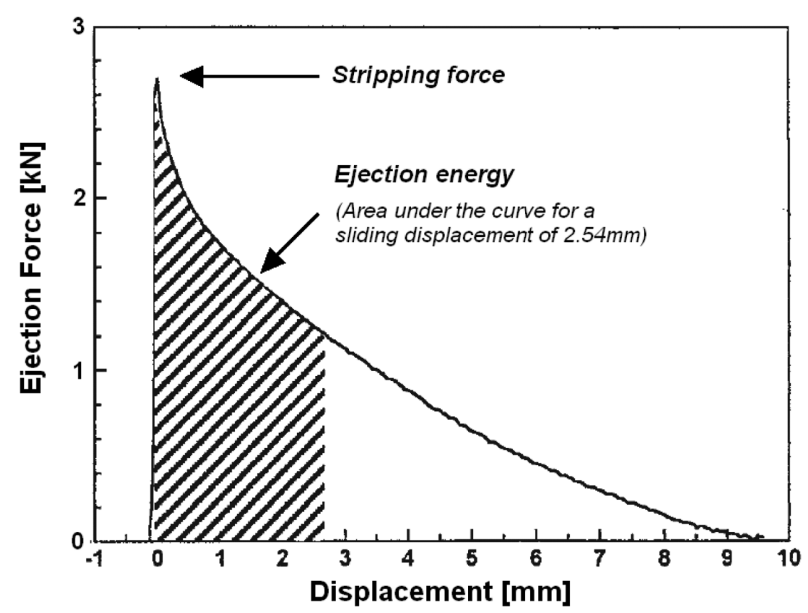

Fig. 1. Typical ejection curve and ejection characteristics measured. slide coefficient varies mainly as a function of the friction coefficient at die walls. The evolution of the coefficient of friction and the stress ratio during compaction is discussed elsewhere [29].

A complete ejection curve, as recorded by the PTC, is shown in Figure 1. The stripping pressure corresponds to the maximum ejection force, developed at the start the ejection process divided by the friction surface area. The ejection unit energy is defined, by the PTC developer, as the energy required to move the compact from the $0.01 \mathrm{~mm}$ to the 2.55 $\mathrm{mm}$ punch position (area under the curve within this interval) divided by the friction area of the test compact and by the travel distance $(2.54 \mathrm{~mm})$. The unit is $\mathrm{N}^{*} \mathrm{~m} / \mathrm{m}^{2} / \mathrm{m}$ or $\mathrm{J} / \mathrm{m}^{3}$.

\section{RESULTS AND DISCUSSION}

\subsection{Particle size and morphology}

Images of the iron and titanium powders used in this study are shown in Fig. 2. The first difference that can be noticed between $\mathrm{Fe}$ and $\mathrm{Ti}$ powders is their particle morphology. Iron ASC100.29 has an irregular morphology, typical of powder particles produced by water atomization. Among the three Ti powders, Batch 2 and Batch 3 particles seem to be more irregular in shape, while Batch 1 seems to be more angular. The angular morphology of $\mathrm{Ti}$ powders derives from the HDH process, in which titanium is hydrogenated in order to make it brittle, which provides these fragile fracture surfaces to the powder particles after milling. Then this powder is dehydrogenated to be converted back to metal Ti and the particles retain their angular morphology from the former hydrogenated particles. The $\mathrm{HDH}$ process is a relatively low-cost way to produce Ti powders with low oxygen and low chlorine contents [30], which is essential to obtain the highest mechanical properties of $\mathrm{Ti}$.

Figure 3 shows the volume weighed particle size distribu-

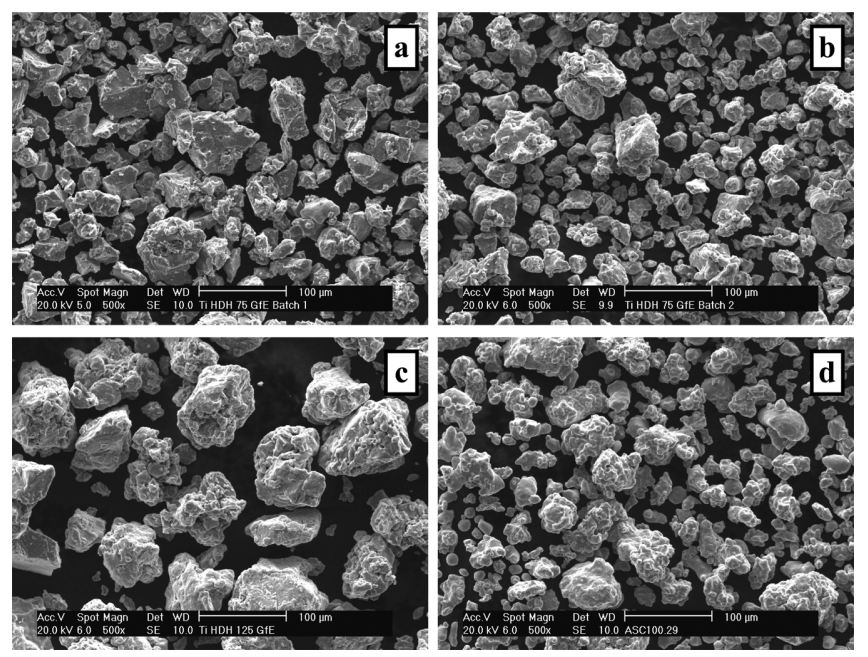

Fig. 2. SEM images of the different powders. (a) Ti-Batch 1, (b) TiBatch 2, (c)Ti-Batch 3, (d) Fe ASC100.29. 

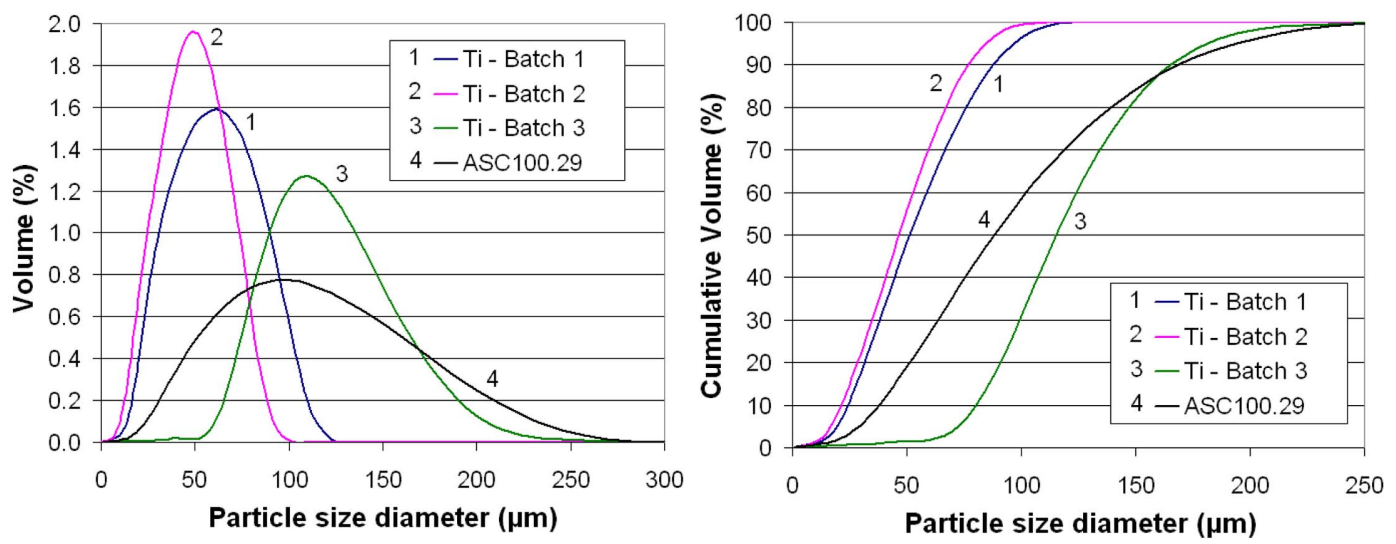

Fig. 3. Particle size distributions (left), and cumulative distributions (right) for the four powders tested.

Table 2. Particle size characteristic parameters of the different powders

\begin{tabular}{ccccc}
\hline & $\begin{array}{c}\text { Mean size } \\
{[\mu \mathrm{m}]}\end{array}$ & $\begin{array}{c}\mathrm{D}_{10} \\
{[\mu \mathrm{m}]}\end{array}$ & $\begin{array}{c}\mathrm{D}_{50} \\
{[\mu \mathrm{m}]}\end{array}$ & $\begin{array}{c}\mathrm{D}_{90} \\
{[\mu \mathrm{m}]}\end{array}$ \\
\hline Ti - Batch 1 & 54 & 24 & 51 & 88 \\
Ti - Batch 2 & 48 & 21 & 47 & 77 \\
Ti - Batch 3 & 119 & 80 & 115 & 166 \\
Fe ASC100.29 & 97 & 38 & 88 & 169 \\
\hline
\end{tabular}

tions (left) as well as the cumulative volume particle size distributions (right) for all the powders tested. Batch 1 has a slightly higher mean size and slightly wider distribution size than Batch 2 and Batch 3 have approximately the same distribution shape, but displaced. Fe ASC100.29 shows a different distribution shape, clearly wider than all the others. The characteristic parameters extracted from the particle size distributions are summarized in Table 2.

\subsection{Composition and hardness}

In relation with the purity of the powders, it is known that little content of interstitial elements (oxygen, carbon, nitrogen and hydrogen) contributes to dramatically change the mechanical properties of titanium. These interstitials increase the elastic modulus, the yield strength and reduce the ductility of titanium [31]. Nitrogen has generally the most significant effect followed by oxygen and carbon [32,33]. While nitrogen and carbon are usually not found at high concentrations in dense titanium, oxygen is a common contaminant due to the high affinity of titanium for oxygen and the high solubility of oxygen in titanium. The total content of interstitial, especially oxygen, is normally higher in the powder particles with the lower particle size due to their higher specific surface. The analyses of these impurities have been determined for the four powders and are summarized in Table 3 .

$$
\mathrm{O}_{\mathrm{Eq}}(\% \mathrm{at})=\mathrm{O}+1.96 * \mathrm{~N}+0.52 * \mathrm{C}
$$

Ti - Batch 1 and Batch 2 have very similar oxygen content, but their nitrogen is significantly different, what is consistent with the microhardness values. Indeed, the nitrogen content of Batch 2 is about $10 \mathrm{X}$ higher than Batch 1 and the $\mathrm{HV}_{0.01}$ of Batch 2 is about $30 \%$ higher than Batch 1. Conrad et al. [31] proposed an equivalent oxygen equation to estimate the Vickers hardness. In the equation 3 , the effect of the nitrogen content is $1.96 \mathrm{X}$ that of oxygen and the carbon content is $0.52 \mathrm{X}$ of oxygen. Table 3 gives the $\mathrm{O}_{\mathrm{Eq}}$ as calculated with the actual composition of the powders. However, as showed in works regarding mechanical properties of Ti foams [34], for high specific surface materials, it is important to discriminate the amount of oxygen coming from solid solution from that of the surface oxide layer. As powder particles have a high specific area, the main part of oxygen is located as an oxide layer at the surface of the particles, so this oxygen does not harden the inside of the particles. Then, instead of total oxygen, only the contribution of oxygen in solid solution (inside the volume of the particles) should be considered as a contributor to the mechanical properties of the titanium powder.

Table 3. Hardness and Chemical analyses of $\mathrm{O}, \mathrm{N}, \mathrm{C}$ and $\mathrm{H}$ for the four powders tested

\begin{tabular}{ccccccccc}
\hline & $\begin{array}{c}\text { Hardness } \\
\mathrm{HV}_{0.01}\end{array}$ & $\begin{array}{c}\text { Specific } \\
\text { surface }\left[\mathrm{m}^{2} / \mathrm{g}\right]\end{array}$ & wt.\% O & wt.\% N & ppm H & wt.\% C & $\begin{array}{c}\text { at.\% } \mathrm{O}_{\mathrm{Eq}}{ }^{(1)} \\
\text { (wt.\%) }\end{array}$ & $\begin{array}{c}\text { at.\% O OolEq } \\
(\text { (wt.\%) }\end{array}$ \\
\hline $\mathrm{Ti}-$ Batch 1 & $127 \pm 24$ & 0.09 & $0.319 \pm 0.003$ & $0.008 \pm 0.001$ & $57 \pm 2$ & $0.009 \pm 0.001$ & $1.020(0.343)$ & $0.543(0.182)$ \\
$\mathrm{Ti}-$ Batch 2 & $167 \pm 32$ & 0.1 & $0.343 \pm 0.002$ & $0.098 \pm 0.004$ & $106 \pm 2$ & $0.013 \pm 0.002$ & $1.693(0.572)$ & $1.146(0.385)$ \\
$\mathrm{Ti}-$ Batch 3 & $159 \pm 20$ & 0.05 & $0.250 \pm 0.006$ & $0.069 \pm 0.004$ & $74 \pm 2$ & $0.013 \pm 0.001$ & $1.228(0.414)$ & $0.955(0.321)$ \\
Fe ASC100.29 & $103 \pm 16$ & 0.02 & $0.083 \pm 0.005$ & $0.003 \pm 0.001$ & $4 \pm 2$ & $0.006 \pm 0.001$ & - & - \\
\hline
\end{tabular}

${ }^{(1)}$ Total equivalent oxygen content (at.\%) - see equation 3.

${ }^{(2)}$ Equivalent oxygen calculated with interstitial in solid solution in the powder particles. 


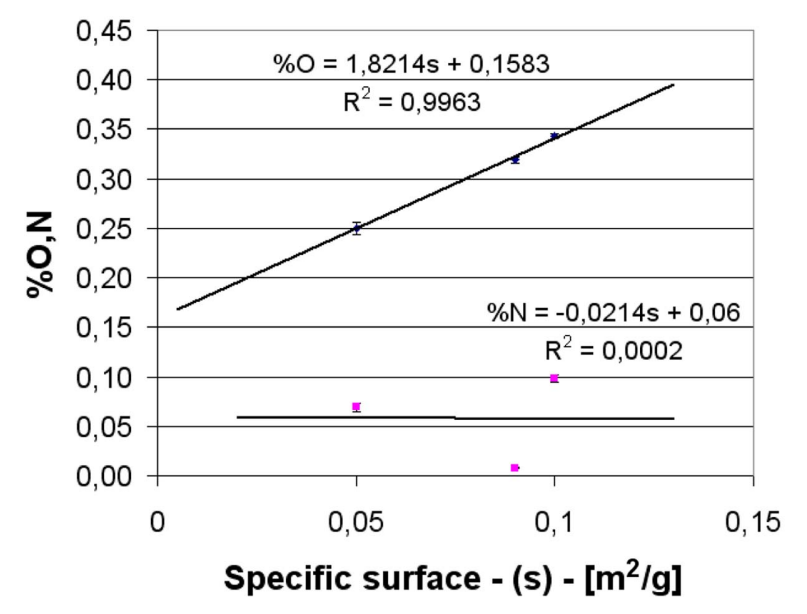

Fig. 4. Correlation between specific surface and $\% \mathrm{O}$ and $\% \mathrm{~N}$.

To separate solid solution contribution from surface contribution, total oxygen can be represented as in equation 4 .

$$
O_{\text {TOTAL }}=O_{\text {Solution }}+C_{\text {Surface }} \cdot A
$$

The $\mathrm{O}_{\text {TOTAL }}$ represents the $\%$ wt. $\mathrm{O}$ in all the powder, measured directly by LECO equipments. $\mathrm{O}_{\text {Solution }}$ is the \%wt. $\mathrm{O}$ in solid solution contained in the volume of the particles. $\mathrm{C}_{\text {Surface }}$ represents 100 times the surface oxygen content $\left(\mathrm{g} / \mathrm{m}^{2}\right)$ of the particles. Finally, A is the specific surface of the powder particles, measured in $\mathrm{m}^{2} / \mathrm{g}$. With this model, specific surface can be correlated with $\mathrm{O}$ and $\mathrm{N}$ contents, as shown in Fig. 4.

From the graph, it is shown that $\mathrm{O}$ content correlates with specific surface, while $\mathrm{N}$ content do not correlate. As shown in Fig. 4, the quality of the fit and the parameters in the regression model lead to the following conclusions:

1. The three $\mathrm{Ti}$ batches have a similar $\mathrm{O}_{\text {Solution }}$ content, which is $0.158 \%$, as this is the part of $\mathrm{O}_{\text {TOTAL }}$ that does not depend on surface. This makes sense in the context that the powders were produced by the same producer, most likely by the same process and that the finer powders are sieved from a larger particle size distribution.

2. The three Ti batches have a similar oxidation condition, with a surface oxygen concentration of $0.01814 \mathrm{~g} / \mathrm{m}^{2}$ which corresponds to a layer $4.3 \mathrm{~nm}$ of $\mathrm{TiO}_{2}$-Anatase. This is in the range of the natural oxide layer thicknesses reported in the literature [34,35].

With this new estimation of oxygen in solution, the equivalent oxygen can be recalculated in all the powders with Conrad Equation (see Table 3). Now, the equivalent oxygen is represented as $\mathrm{O}_{\mathrm{SolEq}}$, as it only considers interstitials in solid solution.

With correlations shown in Fig. 5, while the total $\mathrm{O}$ content does not correlate with hardness, it is clear that hardness has a good correlation with $\mathrm{O}_{\mathrm{SolEq}}$, derived from the good correlation from $\mathrm{N}$, and from the contribution of $\mathrm{O}$ in solid

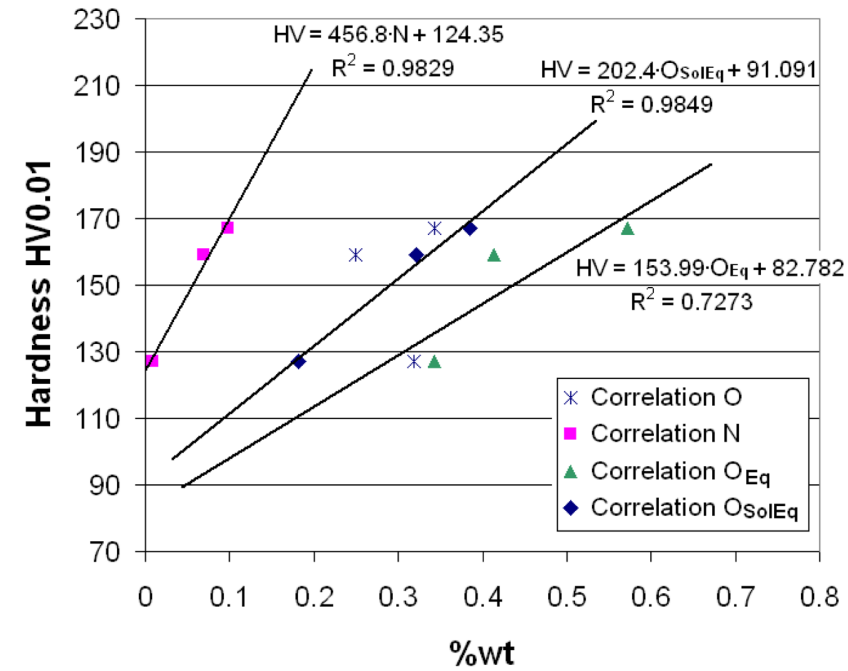

Fig. 5. Correlations of Hardness with $\mathrm{N}, \mathrm{O}_{\mathrm{Eq}}$ and $\mathrm{OSol}_{\mathrm{Eq}}$.

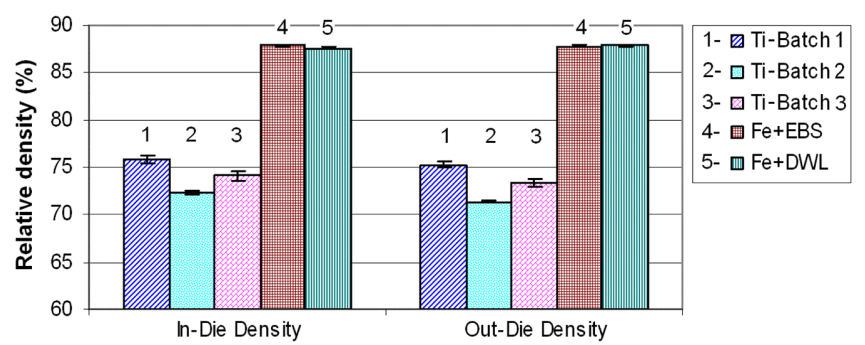

Fig. 6. Relatives green densities of $\mathrm{Fe}$ and Ti powders compacted at $500 \mathrm{MPa}$.

solution. This correlation is better than the one observed between hardness and $\mathrm{O}_{\mathrm{Eq}}$ derived from the total $\mathrm{O}$ content.

\subsection{Compressibility of titanium and iron powders}

The compressibility of the different powders was evaluated on the instrumented press. Results are presented in Fig. 6. For a compacting pressure of $500 \mathrm{MPa}$ iron powders are, as expected, significantly more compressible than titanium powders, respectively $\sim 88 \%$ vs. $72-76 \%$ of the theoretical density. The same tendency is observed both for the green density (or out-die density) and the in-die density (under 500 MPa loading). In addition, the compressibility of both the iron powders compacted either with admixed lubricant (Fe+EBS) or with die wall lubricant $(\mathrm{Fe}+\mathrm{DWL})$ is quite the same. Regarding the compressibility of titanium, there were differences in compressibility between the two batches of the same type of powder $(75.9 \%$ vs. $72.3 \%$ respectively for Batch 1 and Batch 2). Batch 3 had a compressibility that lies between both batches.

The complete compressibility curves can be used to better understand the compressibility behaviour of each powder (see Fig. 7). As an example, while iron powders have similar compressibility at $500 \mathrm{MPa}$, iron powder with admixed lubricant have higher compressibility at lower pressures than 


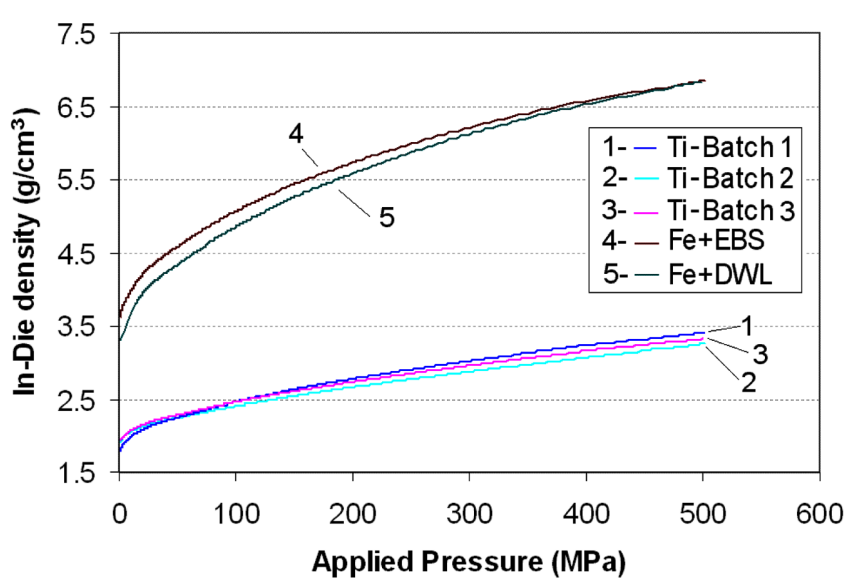

Fig. 7. Compressibility curves of Fe and Ti powders.

iron powder containing compacted with die wall lubrication. This result has already been well described by Ward and Billington [36]: the admixed lubricant improves the compressibility by enabling a better rearrangement of particles and by decreasing friction between particles.

The three titanium powders tested show different compressibility curves that also vary with the compacting pressure (see Fig. 8). For pressures higher than $200 \mathrm{MPa}$, it is clear that Batch 1 has a significantly higher compressibility than Batch 2, while Batch 3 presents an intermediate compressibility.

At the very beginning of compaction, however, Batch 1 yields lower densification as compared to Batch 2 and Batch 3 (see Fig. 8(b)), where Batch 1 presents the lowest apparent density values and, therefore, this powder has the lowest initial packing in-die density $\left(1.8 \mathrm{~g} / \mathrm{cm}^{3}\right.$ vs. $1.9 \mathrm{~g} / \mathrm{cm}^{3}$ for the other titanium powders). This behaviour follows the measure of apparent density presented in Fig. 9. The three titanium powders showed significant difference in terms of

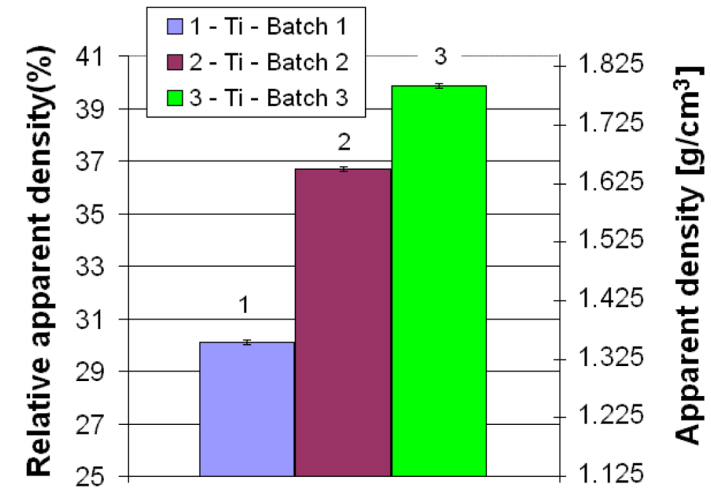

Fig. 9. Apparent density of Ti powders measured with a Carney flowmeter.

flowability: Batch 1 did not flow freely on Hall flowmeter [19], while Batch 2 and Batch 3 flowed on Hall funnel. The Batch 1 powder did neither flow freely in a Carney flowmeter [20]. These differences in flowability seems to be related to the angular particle morphology of Batch 1, different from the irregular morphology of Batch 2 and 3. In order to achieve the apparent density measurement, the flow in the Carney flowmeter, the flow was helped with the aid of a pin. Despite the fact that the supplier categorised both powders Batch 1 and Batch 2 as the same product, these powders are significantly different on flowability and chemistry standpoints.

\subsection{Study of compacting behaviour}

To better understand the compacting behaviour of these titanium powders, the quantification of the key properties or factors affecting the densification, namely the friction at die walls and the powder intrinsic compressibility was attempted. Table 4 and Fig. 10(a) show the applied pressures recorded on the instrumented press as well as the calculated net pres-

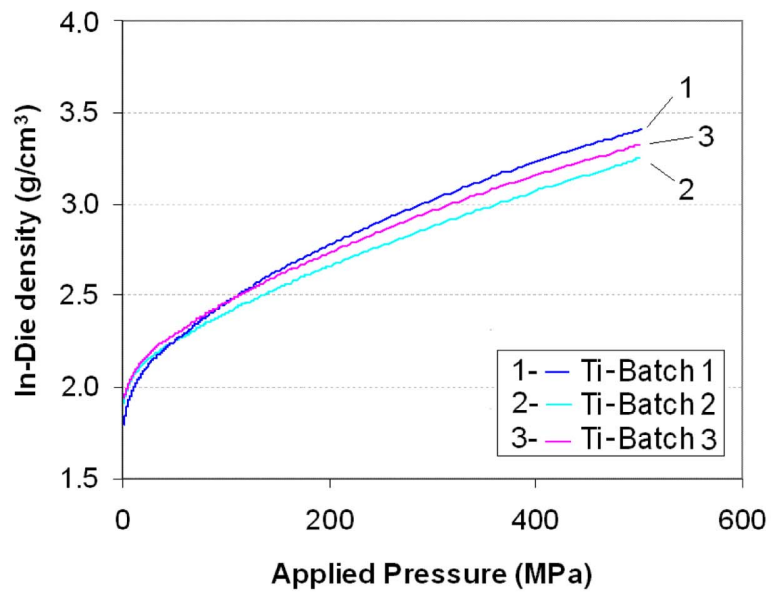

(a)

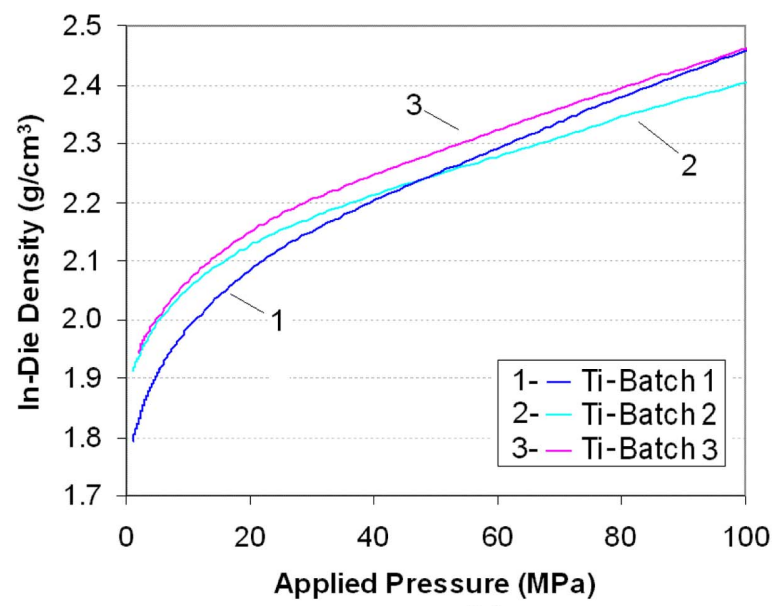

(b)

Fig. 8. (a) Compressibility curves of the three titanium powders and (b) details of the initial stage of the compressibility curves. 
Table 4. Compacting behaviour of the powders tested at a given in-die density

\begin{tabular}{|c|c|c|c|c|c|}
\hline & & In-die Density $\left(\mathrm{g} / \mathrm{cm}^{3}\right)$ & Papplied (MPa) & Pnet (MPa) & Slide Coefficient \\
\hline \multirow{3}{*}{ Ti powders } & $\mathrm{Ti}$ - Batch1 & 3.25 & 4057 & 3244 & 0.560 .04 \\
\hline & $\mathrm{Ti}-\mathrm{Batch} 2$ & 3.25 & 5005 & 4132 & 0.620 .02 \\
\hline & Ti - Batch 3 & 3.25 & 44813 & 3543 & 0.550 .04 \\
\hline \multirow{2}{*}{ Fe Powders } & $\mathrm{Fe}+\mathrm{EBS}$ & 6.8 & 4831 & 4231 & 0.6900 .003 \\
\hline & $\mathrm{Fe}+\mathrm{DWL}$ & 6.8 & 4923 & 4595 & 0.850 .02 \\
\hline
\end{tabular}

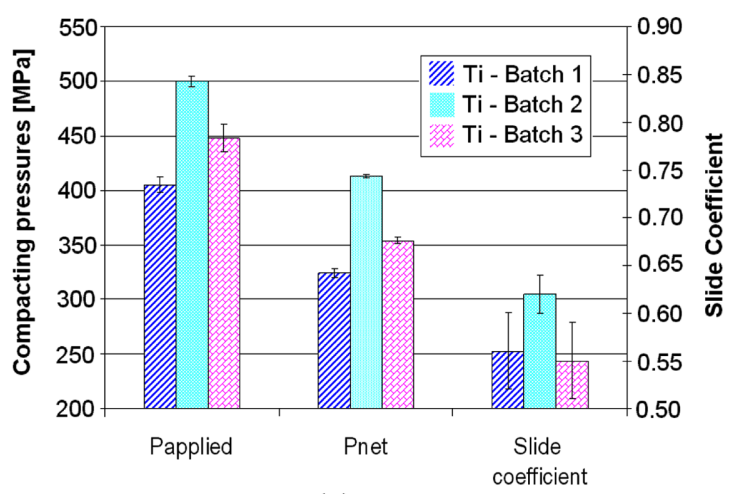

(a)

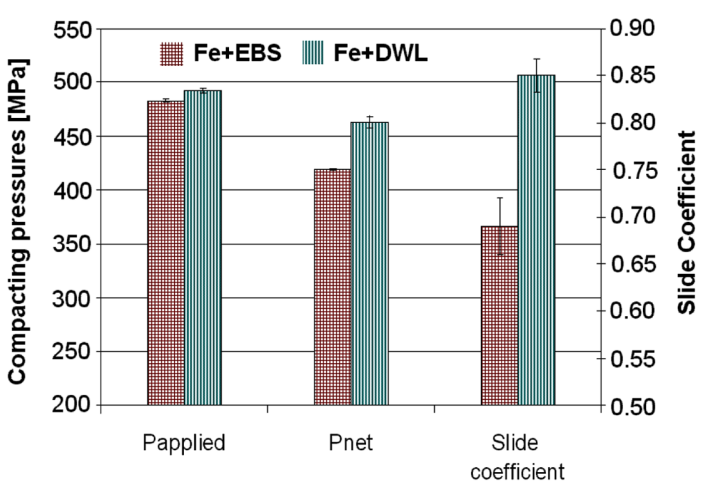

(b)

Fig. 10. Applied and net pressures and slide coefficient at a given in-die density of $3.25 \mathrm{~g} / \mathrm{cm}^{3}$ for (a) Ti powders, and $6.8 \mathrm{~g} / \mathrm{cm}^{3}$ for (b) Fe powders.

sures and slide coefficients observed at a given specific indie density of $3.25 \mathrm{~g} / \mathrm{cm}^{3}$ ( $\sim 72 \%$ of theoretical density) for the three titanium powders tested. These density values were chosen in order to compare the powders at a common value near the maximum density reached at $500 \mathrm{MPa}$ in all the powders. In the case of Fe powders, the selected density was $6.8 \mathrm{~g} / \mathrm{cm}^{3}$ ( $\sim 87 \%$ of the theoretical density), value being close to the maximum density reached in Fe powders at $500 \mathrm{MPa}$. The results for Fe powders are shown in Table 4 and Fig. 10 (b).

Regarding iron powders, the compressibility of both powders is quite similar, as the applied pressure required to reach $6.8 \mathrm{~g} / \mathrm{cm}^{3}$ is close for the two lubrication conditions tested (Papplied $\sim 492 \mathrm{MPa}$ and $483 \mathrm{MPa}$, i.e. $2 \%$ difference). However, their behaviour during compaction is in fact quite different. Indeed, the iron powders compacted with die-wall lubricant have a significantly lower intrinsic compressibility. Pnet is an $8 \%$ higher in die-wall lubricated powder, meaning that a higher isostatic pressure would be necessary to reach the final density. However, less friction is observed at die walls (slide coefficient of 0.85 , i.e. $19 \%$ higher), which compensates the lower intrinsic compressibility, and results in similar compressibility for the two powders.

Regarding titanium powders, the lower compressibility of Batch 2 and Batch 3 is confirmed. Indeed, these two powders respectively require an applied pressure of $95 \mathrm{MPa}$ and $43 \mathrm{MPa}$ higher than Batch 1 to reach a density of $3 \mathrm{~g} / \mathrm{cm}^{3}, 25$ $\mathrm{g} / \mathrm{cm}^{3}$, which represents an increase of $23 \%$ and $11 \%$ vs. the pressure applied for Batch 1. The same trend is observed for the intrinsic compressibility with a higher net pressure of respectively $89 \mathrm{MPa}$ and $30 \mathrm{MPa}$ for Batch 2 and Batch 3 as compared to Batch 1. On the other hand, a higher slide coefficient was obtained for Batch 2 (0.62 vs. 0.56 and 0.55 ) indicating slightly less friction on die walls with this powder as compared to Batch 1 and Batch 3. This proves that the lower compressibility of Batch 2 could be essentially explained by its significant lower intrinsic compressibility as compared to Batch 1. The higher hardness of Batch 2 as compared to Batch 1, while affecting the compressibility, should explain the slightly lower friction at die walls. In conclusion, even though slight difference in friction was observed between the titanium powders, these results show that in the processing conditions tested, their intrinsic compressibility is the key factor that affects the compressibility of the titanium powders.

Regarding now specifically the friction behaviour of titanium powders, it is noteworthy that for similar lubrication mode (die wall lubrication) the range of their slide coefficient values $(0.55-0.62)$ is significantly lower than for iron powders $(0.85)$ (Table 4 and Fig. 11). This indicates the higher difficulty to compact titanium powders due to higher friction at die walls. At this level of slide coefficient, the level of friction remains however acceptable to enable shaping parts with adequate surface finish. Other studies [16] reported, for similar titanium powders, extremely low slide coefficient, as low as 0.3 , that could cause galling and damages to the diewalls. The standard deviation of slide coefficient observed in this study remains however quite important, in particular for Batch 1 and Batch 3 (see Table 4 and Fig. 10). This could be attributed to the high sensitivity of titanium powders to any slight variation of amount of lubricant applied on the die 


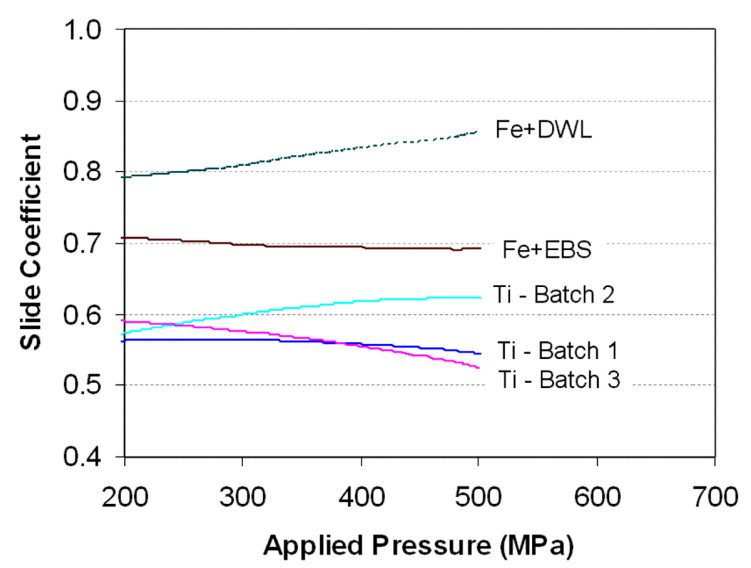

Fig. 11. Curves of Slide Coefficient for the powders tested.

walls. On the other hand, standard deviation of the intrinsic compressibility is quite low whatever the powder tested, which confirms that the Pnet is independent of variation of friction at die walls as mentioned before.

\subsection{Ejection performance}

The ejection performance of the different iron and titanium powders was evaluated from the measurement of the ejection forces during all the ejection cycle. Complete ejection curves are shown in Fig. 12 and the stripping pressures and the unit ejection energies are given in Table 5. The stripping pressure, which corresponds to the peak ejection force at the beginning of ejection, is characterized by the static friction coefficient, while the dynamic friction coefficient influences the energy of ejection along the displacement of the compact in the die on its way to the exit.

Looking at the stripping pressures, similar trend was observed as for the slide coefficient during compaction. The lower stripping pressure $(5.8 \mathrm{MPa})$ was obtained with the die-wall lubricated Fe powder, followed by the Fe powder with internal lubrication (15.9 MPa).

All Ti powders had a similar stripping pressure value

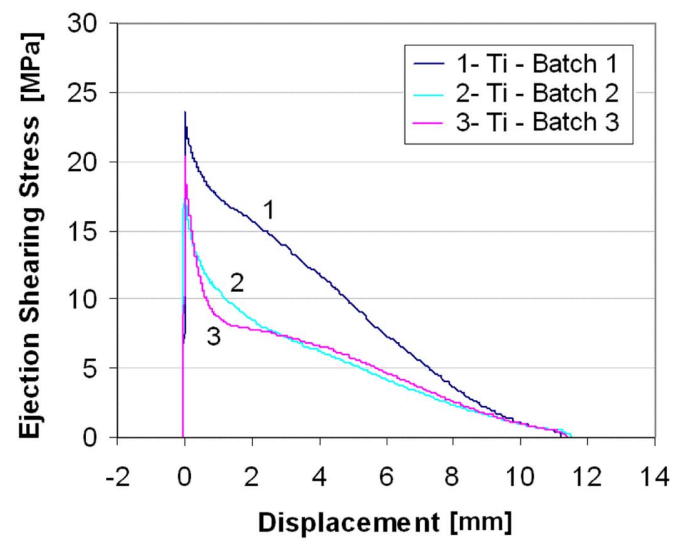

Table 5. Ejection characteristics of the different Fe and Ti powders compacted at $500 \mathrm{MPa}$

\begin{tabular}{ccc}
\hline Powder & $\begin{array}{c}\text { Stripping Pressure } \\
{[\mathrm{MPa}]}\end{array}$ & $\begin{array}{c}\text { Unit Ejection Energy } \\
{\left[\mathrm{MJ} / \mathrm{m}^{3}\right]}\end{array}$ \\
\hline $\mathrm{Ti}-$ Batch 1 & $22.9 \pm 2.8$ & $16.2 \pm 2.4$ \\
$\mathrm{Ti}-$ Batch 2 & $18.9 \pm 1.1$ & $11.2 \pm 1.2$ \\
$\mathrm{Ti}-$ Batch 3 & $20.6 \pm 1.7$ & $9.9 \pm 0.9$ \\
$\mathrm{Fe}+$ EBS & $15.9 \pm 0.1$ & $10.6 \pm 0.2$ \\
$\mathrm{Fe}+\mathrm{DWL}$ & $5.8 \pm 1.2$ & $4.4 \pm 0.7$ \\
\hline
\end{tabular}

around $20 \mathrm{MPa}$ with a slightly higher value for Batch $1(\sim 10$ $\%$ higher). These significantly higher values of ejection pressures of $\mathrm{Ti}$, as compared to $\mathrm{Fe}$ powders have also been reported by Hovanski et al. [14]. As for the slide coefficient, the standard deviation of the stripping pressures of all powders compacted with die wall lubrication is quite important, and in particular for Batch 1 and Batch 3 (see Table 5). Again, this could be attributed to the high sensitivity of titanium powders to any slight variation of amount of lubricant applied on the die walls.

Looking specifically to parts compacted with die wall lubrication, it is clear that Ti powders lead to significantly higher ejection energies than Fe powders, with ejection energies twice higher for Batch 2 and Batch 3 (respectively 9.9 $\mathrm{MPa}$ and 11.2 MPa), and four times higher for Batch 1 (16.2 $\mathrm{MPa}$ ) as compared to $4.4 \mathrm{MPa}$ for Fe powders.

\subsection{Interpretation of titanium powders compressibility results}

In summary, the compressibility results of the titanium powders used in this study led to the following observations: (a) compressibility is inversely proportional to the Vickers hardness, (b) compressibility is mainly correlated to the intrinsic compressibility, (c) compressibility is not correlated to the sliding coefficient and (d) compressibility is not correlated to the apparent density or flowability.

The difference in intrinsic compressibility among the three Ti HDH powders arrive from the strengthening of the pow-

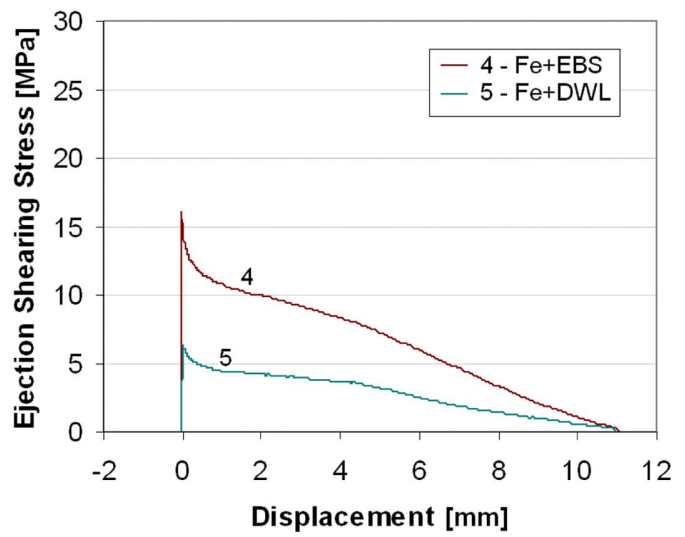

Fig. 12. Ejection curves of the different $\mathrm{Ti}$ and Fe powders compacted at $500 \mathrm{MPa}$. 
Table 6. Compressibility data for various Ti powders [17,18]

\begin{tabular}{cccccc}
\hline Reference & Powder & Condition & Equivalent oxygen content (\%wt) & Mean Particle Size $(\mu \mathrm{m})$ Relative Green Density (\%) \\
\hline \multirow{2}{*}{ This study } & Ti-Batch 1 & & 0.34 & 54 & $75 \%$ \\
& Ti-Batch 2 & \multirow{2}{*}{$500 \mathrm{MPa}$} & 0.57 & 48 & $72 \%$ \\
& Ti-Batch 3 & & 0.41 & 50 & $73 \%$ \\
\hline Laptev, 2005 & Ti HDH & $500 \mathrm{MPa}$ & 0.50 & 97 & $73 \%$ \\
\hline \multirow{2}{*}{ Takamiya, 2004 } & Ti HDH (TC150) & \multirow{2}{*}{$500 \mathrm{MPa}$} & 0.16 & 22 & $85 \%$ \\
& Ti HDH (TC459) & & 0.27 & $83 \%$ \\
\hline
\end{tabular}

ders with the solid solution of interstitials dominated by the nitrogen content effect. This is seen with the increase of Vickers hardness which is directly correlated to the increase of the yield strength. Indeed, Batch 1 powder, despite the fact that it has the lowest apparent density, reaches the highest in-die and out-die densities due to its lower equivalent oxygen (or hardness). Conversely, Batch 2 powder, despite the fact that it has the highest slide coefficient and higher apparent density, reaches the lowest densities due to its high equivalent oxygen. Data from other authors $[17,18]$ has been used to validate this hypothesis. Table 6 shows the correlation between the equivalent oxygen and the compressibility. One should notice that the correction for the surface contribution on the equivalent oxygen has not been applied since the specific surfaces were not available in other authors work. For a compacting pressure of $500 \mathrm{MPa}$, the relative density is inversely proportional to the equivalent oxygen powder of the Ti HDH powders. These results show also that the equivalent oxygen content of the Ti powders has a stronger effect on the compressibility than the particle size. This effect is also seen in stainless steels $\mathrm{P} / \mathrm{M}$ where the interstitials content (mainly nitrogen and carbon) of the powder affects the hardness, the yield strength and the workhardening of these materials and, therefore, their compressibility [37].

The results of this study also suggest a strong interaction between the titanium compact and the die wall. Indeed, the sliding coefficients are much lower than the values obtained for iron powders for both internal or die wall lubrications. In addition, the stripping pressures and the unit ejection energies of titanium powders are much higher than the iron powders. These results are in accordance with prior art indicating the difficulty in shaping titanium sheets or powders leading to excessive die wear and galling. Recently, Hovanski [9] attributed these phenomena to higher values of die wall friction coefficient of Ti powders vs. Fe powders. The breakage of the titanium oxide layer during compaction and the creation of fresh metallic titanium surfaces more prone to react with the die surfaces should be one explanation to this high friction at die walls. This phenomenon could explain the results obtained on the different Ti powders evaluated in this study. The highest die wall friction was observed for the Batch1 powders having the lowest hardness, the lowest $\mathrm{O}_{\mathrm{Eq}}$ and then the lowest yield strength. This powder should lead therefore to higher level of plastic deformation during compaction and then to higher fresh metallic contacts increasing more friction at die walls than the other Ti powders. The use of both admixed and die wall lubrication should help in both improving the rearrangement of particles and therefore the intrinsic compressibility, and reducing the friction at die walls. The choice of both the internal and external lubricants needs however to be developed and adapted specifically to the characteristics of the titanium properties.

\section{CONCLUSIONS}

Three different Ti HDH powders were pressed at $500 \mathrm{MPa}$ and the results were compared with a commercial Fe powder (ASC100.29). The latter was tested in two conditions: with internal lubricant and with die-wall lubricant. After the tests, the following conclusions are stated:

1. The three Ti HDH powders pressed presented significantly lower compressibility than $\mathrm{Fe}$ atomized powders. This could be attributed both to their lower intrinsic compressibility as well as to their lower slide coefficient, ie the significantly higher loss of pressure during compaction due to friction at die walls. The pressures and energies required to eject the samples were also significantly higher for the $\mathrm{Ti}$ pressed samples than for the Fe samples compacted with the same die wall lubrication method.

2. The compressibility of the three Ti HDH powders was found to be significantly different even though two of them were supplied as equivalent powders by the manufacturer. This could be attributed to differences in their equivalent oxygen content that caused strengthening of the powders. For instance, the Ti powders having the lowest equivalent oxygen had the best intrinsic compressibility, but also the lowest sliding coefficient, indicating higher friction at die walls.

3. The selection of the Ti powder having a low level of interstitials in solid solution, and therefore a low equivalent oxygen content seems to be the key factor to reach high green densities at low compacting pressure. Because higher friction at die walls is observed with low equivalent oxygen content, specific attention should be paid to the lubrication. The use of both admixed and die wall lubrication should help in reducing the friction at die walls. The choice of both the internal and external lubricants needs however to be 
developed and adapted specifically to the characteristics of the titanium properties. In particular, clean lubricants should be used to prevent contamination of the materials by the decomposition residues that will affect its mechanical properties.

\section{ACKNOWLEDGMENTS}

The authors want to acknowledge the contribution and effort of Mr. Paul-Émile Mongeon from Industrial Materials Institute (IMI, Canada), as well as for his teaching and advises during the use of Powder Testing Center located at IMI. Shirley Mercier from IMI and Dr. Begoña Ferrari from Instituto de Cerámica y Vidrio (ICV, Spain), are also acknowledged for their contribution to the experimental work. Authors want to acknowledge Fundación Carlos III and Instituto Álvaro Alonso Barba for the funds supplied during the stay at IMI of P.G. Esteban, and the Spanish Ministry of Education for the funds provided for the research thought the I+D project MAT2006-02458.

\section{REFERENCES}

1. M. J. Donachie, Titanium. A Technical Guide, ASM International, USA (1988).

2. G. Lütjering and J. C. Williams, Titanium. Engineering Materials and Processes, Springer, Berlin-Heidelberg (2003).

3. Summary of Emerging Titanium Cost Reduction Technologies. A Study Performed for US Department of Energy and Oak Ridge National Laboratory. Subcontract 4000023694, in: EHKTechnologies, Vancouver, WA 98664, USA, (2004).

4. G. Crowley, Adv. Mater. Process. 161, 25 (2003).

5. G. Z. Chen, D. J. Fray, and T. W. Farthing, Nature 407 (2000).

6. Opportunities for Low Cost Titanium in Reduced Fuel Consumption, Improved Emissions, and Enhanced Durability Heavy-Duty Vehicles. Subcontract 4000013062, in: EHKTechnologies, Vancouver, WA 98664, USA, (2002).

7. C. A. Lavender, Low-cost titanium evaluation, in: F. P. Report (Ed.) Automotive Lightweighting Materials, Contractor: Pacific Northwest national laboratory (2004).

8. T. E. Norgate and G. Wellwood, Jom 58, 58 (2006).

9. J. C. Williams and E. A. Starke, Acta mater. 51, 5775 (2003).

10. D. Raabe, B. Sander, M. Friak, D. Ma, and J. Neugebauer, Acta mater. 55, 4475 (2007).

11. S. L. Zhu, X. M. Wang, F. X. Qin, and A. Inoue, Mater. Sci. Eng. A 459, 233 (2007).

12. M. Karanjai, R. Sundaresan, G. V. N. Rao, T. R. R. Mohan, and B. P. Kashyap, Mater. Sci. Eng. A 447, 19 (2007).

13. H. J. Rack, J. I. Qazi, Mater. Sci. Eng. C 26, 1269 (2006).

14. Y. Hovanski, C. A. Lavender, and K. S. Weil, Evaluation of the pressing characteristics of commercially pure titanium using an instrumented double acting die, in: 2008 World Congress on Powder Metallurgy \& Particulate Materials,
MPIF, Washington D.C., (2008).

15. S.-T. Hong, Y. Hovanski, C. A. Lavender, and K. S. Weil, J. Mater. Eng. Perform. 13, 382 (2008).

16. A. Simchi and G. Veltl, Powder Metall. 49, 281 (2006).

17. A. Laptev, O. Vyal, M. Bram, H. P. Buchkremer, and D. Stover, Powder Metall. 48, 358 (2005).

18. H. Takamiya, M. Kondoh, and T. Saito, Cost-Affordable Titanium 185-192 (2004).

19. MPIF Standard 04, Method for determination of apparent density of the free-flowing metal powders using the Hall apparatus, in: Metal Powder Industries Federation, (1985).

20. MPIF Standard 28, Method for determination of apparent density of non-the free-flowing metal powders using the Carney apparatus, in: Metal Powder Industries Federation, (1985).

21. Powder Testing Center model PTC-03DT, User's manual V-20 (1996).

22. S. St-Laurent, F. Chagnon, Y. Thomas, Study of Compaction and Ejection Properties of Powder Mixes Processed by Warm Compaction, in: Advances in Powder Metallurgy \& Particulate Materials, compiled by H. Ferguson and D.T. Whychell, Metal Powder Industries Federation, Princeton, NJ, pp. 79-91 (2000).

23. P.-E. Mongeon, S. Pelletier, A. Ziani, Die Wall Lubrication method and Apparatus, U.S. Patent $N^{\circ}$ 6,299,690., in.

24. P. Lemieux, S. Pelletier, P.-E. Mongeon, L. P. Lefebvre, Y. Thomas, F. Chagnon, A New Approach to Die Wall Lubrication for P/M Applications, in: Advances in Powder Metallurgy \& Particulate Materials, compiled by B. Eisen and S. Kassam, Metal Powder Industries Federation, Princeton, NJ, pp. 1-13 (2001).

25. S. Roure, D. Bouvard, P. Dorémus, and E. Pavier, Powder Metall. 42, 164, (1999).

26. P. Mosbah, D. Bouvard, F. Ouedraogo, and P. Stutz, Powder Metall. 40, 269 (1997).

27. Y. Thomas, S. Pelletier, and J. M. McCall, Effect of compaction temperature on the lubrication behavior of different lubricant/steel powder compositions, in: Advances in Powder Metallurgy \& Particulate Materials, compiled by J. J. Oakes and J. H. Reinshagen, Metal Powder Industries Federation, Princeton, NJ, USA, pp. 11.25-11.38 (1998).

28. Y. Thomas, L. Azzi, T. Baazi, S. Pelletier, Shaping Stainless Steel Powders Using Die Wall Lubrication, in: Advanced in Powder Metallurgy \& Particulate Materials, compiled by C. Ruas and T.A. Tomlin, Metal Powder Industries Federation, Princeton, NJ, USA, 2005, pp. 3.84-83.96.

29. S. Turenne, C. Godère, Y. Thomas, and P. E. Mongeon, Powder Metall. 42, 263 (1999).

30. E. Fukasawa, R. Murayama, and W. Kagohashi, Characteristics of High-Purity Titanium Powder by HDH Process, in: F. H. Froes, I. L. Caplan (Eds.), Titanium '92: Science and Technology, Vols 1-3, pp. 919-926 (1993).

31. H. Conrad, Prog. Mater. Sci. 26, 123 (1981).

32. R. I. Jaffee, H. R. Ogden, and D. J. Maykuth, T. Am. I. Min. 
Met. Eng. 188, 1261 (1950).

33. R. I. Jaffee and I. E. Campbell, T. Am. I. Min. Met. Eng. 185, 646 (1949).

34. L. P. Lefebvre and E. Baril, Adv. Eng. Mater. 10, 868 (2008).

35. M. Textor, C. Sittig, V. Frauchiger, S. Tasatti, and D. M. Brunette, Properties and Biological Significance of Natural
Oxide Films on Titanium and Its Alloys, in: Springer (Ed.) Titanium in Medicine (2001).

36. M. Ward and J. C. Billington, Powder Metall. 22, 201 (1979).

37. E. Klar, P. Samal, K., Powder Metallurgy of Stainless Steels: Processing, Microstructures, and Properties, ASM International (2007). 